\title{
Electrocatalytic measurement of methionine concentration with a carbon nanotube paste electrode modified with benzoylferrocene
}

\author{
Hadi BEITOLLAHI a,*, Alireza MOHADESI b, Farzaneh GHORBANI b, Hassan KARIMI MALEH ${ }^{c}$, \\ Mehdi BAGHAYERI ${ }^{\text {, }}$ Rahman HOSSEINZADEH $\mathrm{e}$ \\ a Environment Department, Institute of Science and High Technology and Environmental Sciences, Graduate University of Advanced Technology, Kerman, \\ Iran \\ b Department of Chemistry, Payame Noor University, 19395-4697, Tehran, Iran \\ c Department of Chemistry, Graduated University of Advanced Technology, Kerman, Iran \\ d Department of Chemistry, Faculty of Science, Hakim Sabzevari University, PO Box 397, Sabzevar, Iran \\ e Department of Organic Chemistry, Faculty of Chemistry, University of Mazandaran, Babolsar, Iran
}

\section{A R T I C L E I N F O}

\section{Article history:}

Received 7 February 2013

Accepted 15 March 2013

Published 20 July 2013

\section{Keywords:}

Methionine

Electrocatalysis

Carbon nanotube

Chemically modified electrode

Voltammetry

Benzoylferrocene

\section{A B S T R A C T}

A benzoylferrocene modified multi-wall carbon nanotube paste electrode for the measurement of methionine (MET) concentration is described. MET electrochemical response characteristics of the modified electrode in a phosphate buffer solution of $\mathrm{pH} 7.0$ were investigated by cyclic voltammetry, square wave voltammetry, and chronoamperometry. Under optimized conditions, the square wave voltammetric peak current of MET increased linearly with MET concentration in the range of $1.0 \times 10^{-7}$ to $2.0 \times 10^{-4} \mathrm{~mol} / \mathrm{L}$. The detection limit was $58.0 \mathrm{nmol} / \mathrm{L}$ MET. The diffusion coefficient $(D$ $\left.=5.62 \times 10^{-6} \mathrm{~cm}^{2} / \mathrm{s}\right)$ and electron transfer coefficient $(\alpha=0.4)$ for MET oxidation were also determined. The sensor was successfully applied for the measurement of MET concentration in human urine.

(C) 2013, Dalian Institute of Chemical Physics, Chinese Academy of Sciences. Published by Elsevier B.V. All rights reserved.

\section{Introduction}

Electrochemical methods for the detection of inorganic and organic compounds are selective and sensitive [1-4]. Chemically modified electrodes (CMEs) are extensively researched for applications in medical diagnostics, food analysis, and environmental monitoring [5-9]. An important property of CMEs is their ability to catalyze the electrode process to significantly decrease the overpotential and give more selective interaction of the electron mediator with the target analyte. These electrodes can enhance the selectivity in the electroanalytical methods.
Carbon paste electrodes (CPEs) represent one of the most convenient materials for the preparation of modified electrodes. CPEs are widely applied in both electrochemical studies and electroanalysis for their advantages such as very low background current (compared to solid graphite or noble metal electrodes), easy to prepare, low cost, large potential window, simple surface renewal process, and ease of miniaturization [10-13].

As a relatively novel nanomaterial, carbon nanotubes (CNTs) have received attention due to their small dimension and structure sensitive properties. In electroanalytic and bioanalytic applications, the high electrical conductivity and elec-

*Corresponding author. Tel: +98-3426226613; Fax: +98-3426226617; E-mail: h.beitollahi@yahoo.com 
trocatalytic activity of CNTs allow them to be used as the electrode material to mediate electron transfer reactions $[14,15]$. Several authors have reported the excellent electrocatalytic properties of CNTs in the redox reactions of different biomolecules [16-20].

Protein and amino acid analysis continues to be an important area of research in the field of chemical and biochemical analysis. Sulfur-containing molecules are widely present in plants and living organisms and they play an important role in living systems [21]. Methionine (MET) is an essential sulfur-containing proteinogenic amino acid with an important role in biological methylation reactions. It is the main supply of sulphur in the diet, and it prevents disorders in hair, skin, and nails. Moreover, it helps to reduce cholesterol levels by increasing lecitin production in liver, and it is also a natural chelating agent for heavy metals. MET can be present at different concentration levels from near $0.1 \%(\mathrm{~m} / \mathrm{v})$ in some drugs to $10^{-5} \mathrm{~mol} / \mathrm{L}$ in blood plasma [22]. Homocysteine is an intermediate product of MET metabolism [23]. A defective metabolism of MET would result in hyperhomocysteinemia, which has been established as an independent risk factor for vascular diseases in humans $[24,25]$. It has been reported that the improper conversion of MET leads to atherosclerosis [26]. MET deficiency has been reported to cause toxaemia, muscle paralysis, depression, and impaired growth [27]. Hence, the detection of MET is very important from a clinical point of view.

Several methods have been proposed for the measurement of MET concentration including flow injection [28,29], chromatography [30,31], capillary electrophoresis [23], spectrophotometry [32], chemiluminescence [33], atomic absorption [34], and colorimetric [35,36] and enzymatic methods [37]. These methods have several disadvantages, such as high cost, long analysis time, and low sensitivity, and therefore they are unsuitable for routine analysis. On the other hand, the measurement of MET concentration by electrochemical methods has several advantages, which include high sensitivity, selectivity and reproducibility. The measurement of MET concentration with a chemically modified electrode is an attractive method. Only few reports are available in the literature for the measurement of MET concentration by electrochemical methods [38-43].

No study has been reported on the electrocatalytic oxidation of MET with a benzoylferrocene (BF) modified multi-wall carbon nanotube paste electrode (BFCNPE). Thus, in the present work, we described the preparation and suitability of a BFCNPE as the electrode in the electrocatalysis and measurement of MET concentration in an aqueous buffer solution. To demonstrate the catalytic activity of the modified electrode in the electrooxidation of MET, we examined its use for the voltammetric measurement of MET concentrationin in urine samples.

\section{Experimental}

\subsection{Apparatus and chemicals}

The electrochemical measurements were performed with an Autolab potentiostat/galvanostat (PGSTAT 12, Eco Chemie,
Netherlands). The experimental conditions were controlled by the General Purpose Electrochemical System (GPES) software. A conventional three electrode cell was used at $(25 \pm 1){ }^{\circ} \mathrm{C}$. A $\mathrm{Ag} / \mathrm{AgCl} / \mathrm{KCl}(3.0 \mathrm{~mol} / \mathrm{L}$ ) electrode, a platinum wire, and the BFCNPE were used as the reference, auxiliary, and working electrodes, respectively. A Metrohm $710 \mathrm{pH}$ meter was used for pH measurements.

All solutions were freshly prepared with doubly distilled water. MET and all other reagents were analytical grade purchased from Merck (Darmstadt, Germany). The buffer solutions were prepared from orthophosphoric acid and its salts in the pH range of 2.0 to 11.0. Multiwalled carbon nanotubes (purity > $95 \%$ ) with o.d. between 10 and $20 \mathrm{~nm}$, i.d. between 5 and 10 $\mathrm{nm}$, and tube length from 0.5 to $200 \mu \mathrm{m}$ were obtained from Nanostructured \& Amorphous Materials, Inc.

\subsection{Synthesis of benzoylferrocene}

A mixture of aluminum chloride (10.8 g, $80.66 \mathrm{mmol}$ ) and benzoyl chloride (11.3 g, $80.66 \mathrm{mmol})$ in $100 \mathrm{ml}$ of dry methylene chloride was added to a solution of ferrocene $(15.0 \mathrm{~g}$, $80.66 \mathrm{mmol}$ ) in $100 \mathrm{ml}$ of dry methylene chloride over a period of $15 \mathrm{~min}$. The mixture was stirred at room temperature for $1 \mathrm{~h}$ and then hydrolyzed with dilute hydrochloric acid $(60 \mathrm{ml}, 3$ mol/L). The organic phase was washed with $\mathrm{NaOH}$ solution (50 $\mathrm{ml}, 1 \mathrm{~mol} / \mathrm{L})$, saturated $\mathrm{NaCl}$ solution $(50 \mathrm{ml})$, and $\mathrm{H}_{2} \mathrm{O}(50 \mathrm{ml})$, and dried over anhydrous sodium sulfate. The solid which remained after evaporation of the solvent was recrystallized from toluene and $n$-hexane to give the pure product in $78 \%$ yield (red solid); mp: $106-108{ }^{\circ} \mathrm{C}$; ${ }^{1} \mathrm{H}$ NMR (400 $\mathrm{MHz} \mathrm{CDCl}_{3}$ ): $\delta 4.17$ (s, $5 \mathrm{H}), 4.58(\mathrm{t}, J=2.5 \mathrm{~Hz}, 2 \mathrm{H}), 4.90(\mathrm{~d}, J=8.4 \mathrm{~Hz}, 2 \mathrm{H})$, 7.44-7.56 (m, $3 \mathrm{H}), 7.90(\mathrm{t}, J=2.5 \mathrm{~Hz}, 2 \mathrm{H}) ;{ }^{13} \mathrm{C} \mathrm{NMR}(100 \mathrm{MHz}$, $\left.\mathrm{CDCl}_{3}\right): \delta 70.22,71.53,72.51,78.25,128.07,128.21,131.45$, 139.87, 199.02 .

\subsection{Preparation of the electrode}

The BFCNPEs were prepared by hand mixing $0.01 \mathrm{~g}$ of $\mathrm{BF}$ with $0.89 \mathrm{~g}$ graphite powder and $0.1 \mathrm{~g}$ CNTs with a mortar and pestle. Then, $0.7 \mathrm{ml}$ of paraffin oil was added to the above mixture and mixed for 20 min until a uniformly wet paste was obtained. The paste was packed into the end of a glass tube (ca. $3.4 \mathrm{~mm}$ i.d. and $15 \mathrm{~cm}$ long). A copper wire inserted into the carbon paste provided the electrical contact. When necessary, a new surface was obtained by pushing some paste out of the tube and polishing with a weighing paper.

For comparison, a BF modified CPE electrode (BF-CPE) without CNTs, CNT paste electrode (CNPE) without BF, and unmodified CPE in the absence of both BF and CNTs were also prepared in the same way.

\section{Results and discussion}

\subsection{Electrochemical properties of BFCNPE}

The BFCNPE was prepared and its electrochemical properties were studied in a $0.1 \mathrm{~mol} / \mathrm{L}$ phosphate buffer solution 


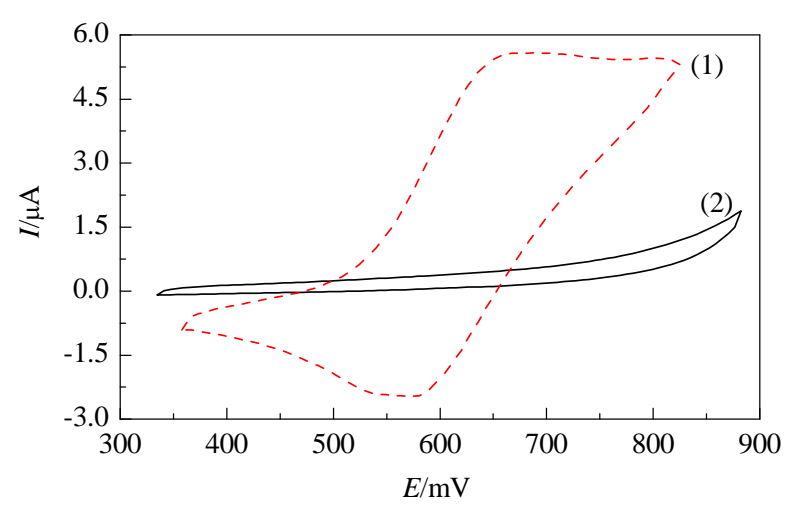

Fig. 1. CV of BFCNPE in $0.1 \mathrm{~mol} / \mathrm{L}$ PBS (pH 7.0) (1) and at the surface of a bare carbon paste electrode at a scan rate $100 \mathrm{mV} / \mathrm{s}(2)$.

(PBS) of pH 7.0 using cyclic voltammetry (CV) (Fig. 1). There were well defined and reproducible anodic and cathodic peaks from the benzoylferrocene/benzoylferricenium redox system, which showed quasireversible behavior in an aqueous medium [44]. The generation of a reproducible surface was examined by $\mathrm{CV}$ data obtained in the optimum solution of $\mathrm{pH} 7.0$ from five separately prepared BFCNPEs (Table 1).

In addition, the long term stability of the BFCNPE was tested over a three week period. CVs recorded after the modified electrode was stored in the atmosphere at room temperature showed a peak potential for MET oxidation that was unchanged and the current signals showed less than $2.2 \%$ decrease relative to the initial response. The antifouling properties of the modified electrode toward MET and its oxidation products were investigated by recording the cyclic voltammograms of the modified electrode before and after use in the presence of MET. Cyclic voltammograms were recorded in the presence of MET after cycling the potential 20 times at a scan rate of 10 $\mathrm{mV} / \mathrm{s}$. The peak potentials were unchanged, and the currents were decreased by less than $2.3 \%$. Therefore, the surface of BFCNPE showed not only sensitivity increase but also decreased fouling by the analyte and its oxidation product.

\subsection{Electrocatalytic oxidation of MET at BFCNPE}

Figure 2 depicts the $\mathrm{CV}$ responses for the electrochemical oxidation of $100.0 \mu \mathrm{mol} / \mathrm{L} \mathrm{MET}$ at unmodified CPE (curve (3)), CNPE (curve (4)), benzoylferrocene modified multi-wall carbon nanotube paste electrode (BFCPE, curve (1)), and BFCNPE (curve (2)). While the anodic peak potential for MET oxidation at the CNPE and unmodified CPE were 900 and $960 \mathrm{mV}$, respectively, the potential at BFCNPE and BFCPE were $\sim 645 \mathrm{mV}$. The peak potential for MET oxidation at the BFCNPE and BFCPE electrodes was shifted by 255 and $315 \mathrm{mV}$ toward negative values compared to CNPE and unmodified CPE, respectively. However, BFCNPE showed a much higher anodic peak

Table 1

Cyclic voltammetric data obtained with the BFCNPE in $0.1 \mathrm{~mol} / \mathrm{L}$ PBS (pH 7.0) at $100 \mathrm{mV} / \mathrm{s}$.

\begin{tabular}{cccccc}
\hline$E_{\mathrm{pa}} * / \mathrm{V}$ & $E_{\mathrm{pc}} / \mathrm{V}$ & $E_{1 / 2} / \mathrm{V}$ & $\Delta E_{\mathrm{p}} / \mathrm{V}$ & $I_{\mathrm{pa}} / \mu \mathrm{A}$ & $I_{\mathrm{pc}} / \mu \mathrm{A}$ \\
\hline $0.645 \pm 1.3$ & $0.540 \pm 1.4$ & $0.592 \pm 1.3$ & $0.105 \pm 1.4$ & $5.2 \pm 1.7$ & $-2.4 \pm 1.6$ \\
\hline
\end{tabular}

*Versus $\mathrm{Ag} / \mathrm{AgCl} / \mathrm{KCl}(3.0 \mathrm{~mol} / \mathrm{L})$ as reference electrode.

All the ' \pm ' values are RSD\% $(n=5)$.

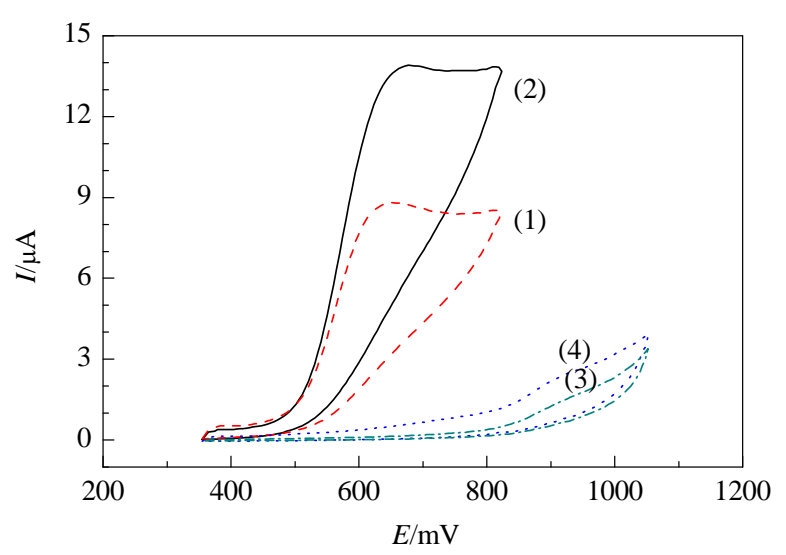

Fig. 2. CVs of BFCPE (1) and BFCNPE (2) in $0.1 \mathrm{~mol} / \mathrm{L}$ PBS (pH 7.0) containing $100.0 \mu \mathrm{mol} / \mathrm{L}$ MET; CVs of CPE (3) and CNPE (4) in 0.1 mol/L PBS (pH 7.0) containing $100.0 \mu \mathrm{mol} / \mathrm{L}$ MET. The scan rate was $10 \mathrm{mV} / \mathrm{s}$.

current for the oxidation of MET compared to BFCPE, indicating that the combination of CNTs and the mediator (BF) significantly improved the performance of the electrode for MET oxidation. The BFCNPE in $0.1 \mathrm{~mol} / \mathrm{L}$ PBS (pH 7.0) and without MET in the solution exhibited a well behaved redox reaction (Fig. 1(1)). The addition of $100.0 \mu \mathrm{mol} / \mathrm{L}$ MET increased the anodic peak current (Fig. 2(2)), indicating a strong electrocatalytic effect [44].

The effect of scan rate on the electrocatalytic oxidation of MET at the BFCNPE was also investigated by CV (Fig. 3(a)). The oxidation peak potential shifted to more positive potentials with increasing scan rate, confirming the kinetic regime in the electrochemical reaction. Also, a plot of peak height $\left(I_{\mathrm{p}}\right)$ versus square root of scan rate $\left(v^{1 / 2}\right)$ was linear in the range of $2-20$ $\mathrm{mV} / \mathrm{s}$, suggesting that at sufficient overpotential the process is diffusion rather than surface controlled [44] (Fig. 3(b)). The Tafel slope (Fig. 3(c)) was obtained from the slope of $E_{\mathrm{p}}$ versus $\log v$ using Eq. (1) [44]:

$$
E_{\mathrm{p}}=b / 2 \log v+\text { constant }
$$

The Tafel slope was $0.098 \mathrm{~V}$ (Fig. 3(c)), which indicates that a one-electron transfer process is the rate limiting step assuming a transfer coefficient $(\alpha)$ of 0.4 .

\subsection{Chronoamperometric measurements}

Chronoamperometric measurements of MET concentration at the BFCNPE were carried out by setting the working electrode potential at $0.7 \mathrm{~V}$ at the first potential step and at $0.5 \mathrm{~V}$ at the second potential step versus $\mathrm{Ag} / \mathrm{AgCl} / \mathrm{KCl}(3.0 \mathrm{~mol} / \mathrm{L})$ for the various concentrations of MET in PBS (pH 7.0) (Fig. 4). For an electroactive material (MET in this case) with a diffusion coefficient of $D$, the current observed for the electrochemical reaction under a mass transport limited condition is described by the Cottrell equation [44]. The best fits of $I$ vs $t^{-1 / 2}$ were obtained for the different concentrations of MET (Fig. 4(b)). The slopes of the straight lines were then plotted versus MET concentration (Fig. 4(c)). From the resulting slope and the Cottrell equation [44]:

$$
I=n F A D^{1 / 2} C_{\mathrm{b}} \pi^{-1 / 2} t^{-1 / 2}
$$



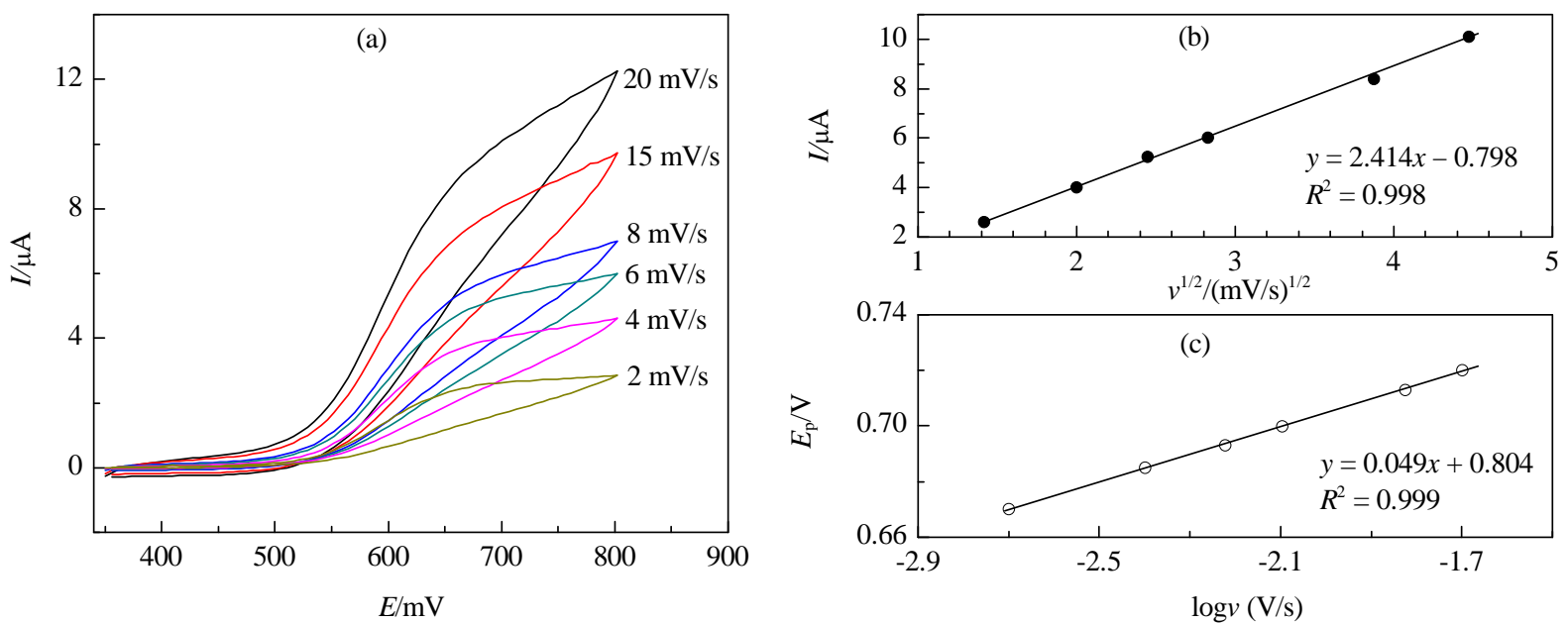

Fig. 3. (a) CVs of BFCNPE in $0.1 \mathrm{~mol} / \mathrm{L}$ PBS (pH 7.0) containing $50.0 \mu \mathrm{mol} / \mathrm{L}$ MET at various scan rates; (b) Variation of anodic peak current vs $v^{1 / 2}$; (c) Anodic peak potential vs $\log v$.
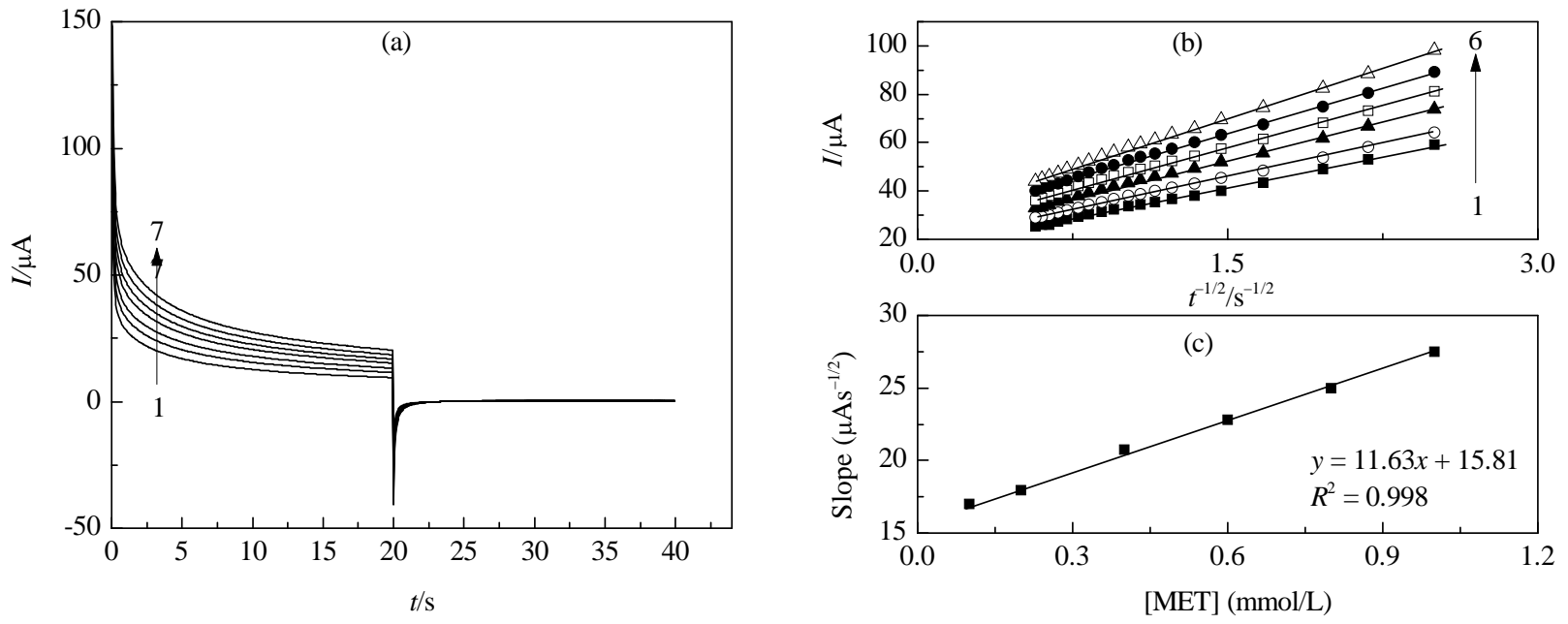

Fig. 4. (a) Chronoamperograms obtained at BFCNPE in $0.1 \mathrm{~mol} / \mathrm{L}$ PBS ( $\mathrm{pH} 7.0$ ) for different concentrations of MET (the numbers 1-7 correspond to $0.0,0.1,0.2,0.4,0.6,0.8$, and $1.0 \mathrm{mmol} / \mathrm{L}$ of MET); (b) Plots of $I$ vs $t^{-1 / 2}$ obtained from chronoamperograms 2-7; (c) Plot of the slope of the straight lines against MET concentration.

Where $D$ and $C_{\mathrm{b}}$ are the diffusion coefficient $\left(\mathrm{cm}^{2} / \mathrm{s}\right)$ and the bulk concentration $\left(\mathrm{mol} / \mathrm{cm}^{3}\right)$, respectively. The mean value of D was $5.62 \times 10^{-6} \mathrm{~cm}^{2} / \mathrm{s}$.

\subsection{Calibration plot and limit of detection}

The square wave voltammetry method was used to determine the concentration of MET (Fig. 5). The plot of peak current versus MET concentration consisted of two linear segments with slopes of 0.634 and $0.049(\mu \mathrm{A} \cdot \mathrm{L}) / \mu \mathrm{mol}$ in the concentration ranges of 0.1 to $10.0 \mu \mathrm{mol} / \mathrm{L}$ and 10.0 to 200.0 $\mu \mathrm{mol} / \mathrm{L}$, respectively. The decrease in sensitivity (slope) in the second linear segment was likely due to kinetic control. The detection limit $(3 \sigma)$ of MET was $58.0 \mathrm{nmol} / \mathrm{L}$. These values are comparable with the values reported by other research groups for the electrocatalytic oxidation of MET at the surfaces of chemically modified electrodes by other mediators (Table 2).

\subsection{Interference study}

The interferences of various foreign species on the measurement of MET concentration were investigated. The tolerance limit was taken as the maximum concentration of the foreign substances, which caused a $\pm 5 \%$ relative error in the measurement. L-lysine, glucose, NADH, acetaminophen, L-asparagine, glycine, folic acid, uric acid, tryptophan, and phenylalanine did not show interference in the measurement of MET but L-cysteine, cysteamine, captopril, and D-penicillamine showed interferences.

\subsection{Measurement of MET concentration in urine samples}

In order to evaluate the analytic applicability of the proposed electrode, it was applied for the measurement of MET concentrationin in urine samples. The results are given in Table 3. Satisfactory agreement of the experimental results was found for the MET concentration. The reproducibility of the method was demonstrated by the small mean relative standard deviation (RSD). 

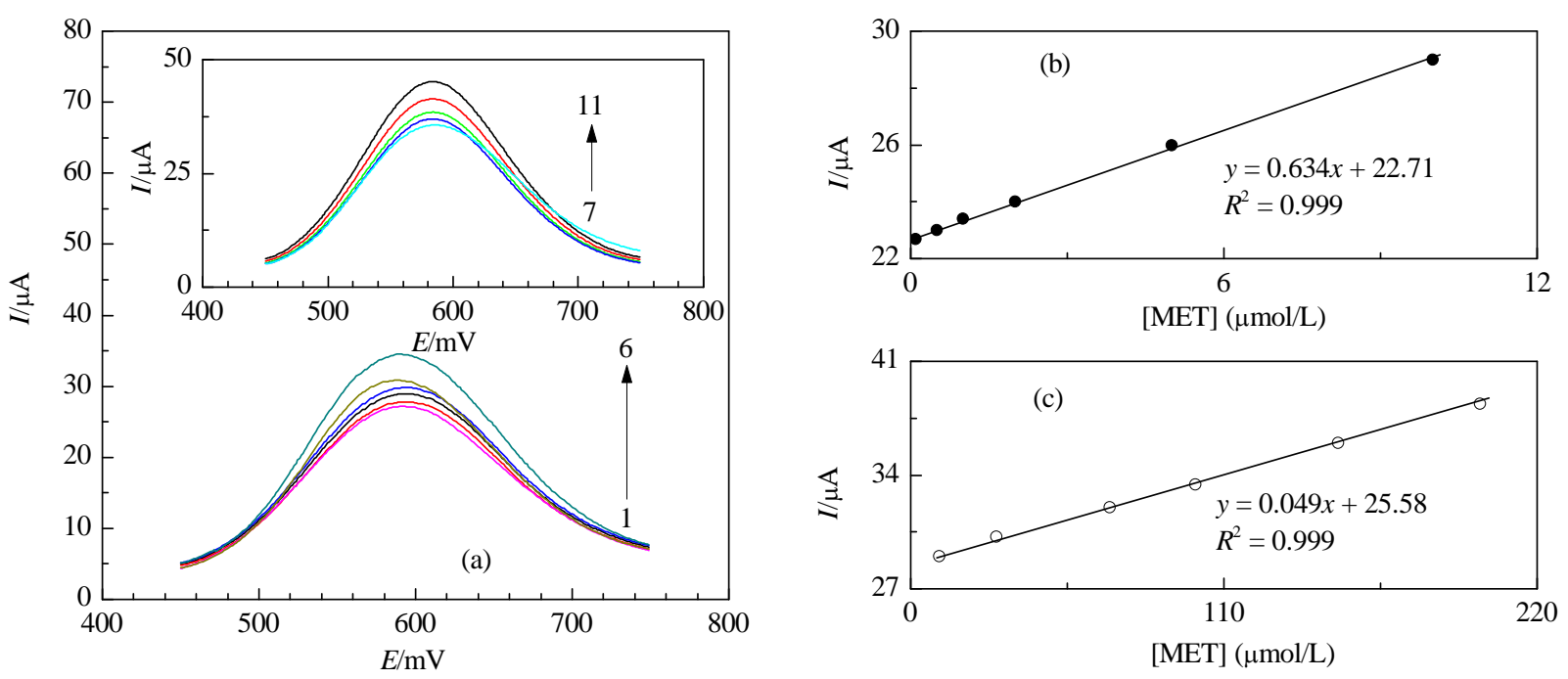

Fig. 5. (a) Square wave voltammetry curves of BFCNPE in $0.1 \mathrm{~mol} / \mathrm{L}$ PBS (pH 7.0) containing different concentrations of MET (the numbers $1-11$ correspond to $0.1,0.5,1.0,2.0,5.0,10.0,30.0,70.0,100.0,150.0$, and $200.0 \mu \mathrm{mol} / \mathrm{L}$ of MET); Plots of the electrocatalytic peak current as a function of MET concentration in the range of 0.1 to $10.0 \mu \mathrm{mol} / \mathrm{L}$ (b) 10.0 to $200.0 \mu \mathrm{mol} / \mathrm{L}$ (c).

Table 2

Comparison of the efficiency of some modified electrodes in the electrocatalysis of MET.

\begin{tabular}{lcccccc}
\hline Electrode & Modifier & Method & $\mathrm{pH}$ & Dynamic range (mol/L) & Limit of detection ( mol/L) & Ref. \\
\hline Carbon paste & Colloidal-gold cysteamine & Voltammetry & 7.0 & $1.0 \times 10^{-6}-1.0 \times 10^{-4}$ & $5.9 \times 10^{-7}$ & {$[22]$} \\
Glassy carbon & Electropolymerized film of & Voltammetry & 4.0 & $5.0 \times 10^{-5}-5.0 \times 10^{-4}$ & $2.7 \times 10^{-8}$ & {$[38]$} \\
& $\begin{array}{l}1,8,15,22-\text { tetraaminophthalocy } \\
\text { anato-copper(II) }\end{array}$ & & & & \\
Glassy carbon & Cobalt hydroxide nanoparticles & Amperometry & 13.0 & $2.45 \times 10^{-4}-1.21 \times 10^{-3}$ & $1.6 \times 10^{-4}$ & {$[45]$} \\
Carbon nanotube paste & BF & Voltammetry & 7.0 & $1.0 \times 10^{-7}-2.0 \times 10^{-4}$ & $5.8 \times 10^{-8}$ & this work \\
\hline
\end{tabular}

Table 3

Use of BFCNPE for the measurement of MET concentrationin in urine samples $(n=5)$.

\begin{tabular}{lccccc}
\hline $\begin{array}{l}\text { Sample } \\
\text { No. }\end{array}$ & $\begin{array}{c}\text { Original content } \\
(\mu \mathrm{mol} / \mathrm{L})\end{array}$ & $\begin{array}{c}\text { Added } \\
(\mu \mathrm{mol} / \mathrm{L})\end{array}$ & $\begin{array}{c}\text { Found } \\
(\mu \mathrm{mol} / \mathrm{L})\end{array}$ & $\begin{array}{c}\text { Recovery } \\
(\%)\end{array}$ & $\begin{array}{c}\text { RSD } \\
(\%)\end{array}$ \\
\hline 1 & - & 15.0 & 14.9 & 99.3 & 2.3 \\
2 & - & 30.0 & 31.1 & 103.7 & 3.4 \\
3 & - & 45.0 & 45.6 & 101.3 & 2.4 \\
4 & - & 60.0 & 58.3 & 97.2 & 1.9 \\
\hline
\end{tabular}

\section{Conclusions}

A benzoylferrocene modified carbon nanotube paste electrode (BFCNPE) was fabricated. The modified electrode showed good electrocatalytic activity for the oxidation of MET and gave a wide linear range ( 0.1 to $200.0 \mu \mathrm{mol} / \mathrm{L})$ with a good detection limit (58.0 nmol/L) for MET concentration. This sensor was successfully applied to determine the MET concentration in urine samples.

\section{References}

[1] Guo Y M, Lin Y, Shi H G, Ran R, Shao Z P. Chin J Catal (催化学报), 2009, 30: 479

[2] Hosseini M G, Abdolmaleki M, Ashrafpoor S. Chin J Catal (催化学 报), 2012, 33: 1817

[3] Beitollahi H, Raoof J B, Hosseinzadeh R. Talanta, 2011, 85: 2128

[4] Mokhtari A, Karimi-Maleh H, Ensafi A A, Beitollahi H. Sens Actua- tors $B, 2012,169: 96$

[5] Jafarian M, Rashvand Avei M, Danaee I, Gobal F, Mahjani M G. Chin J Catal (催化学报), 2010, 31: 1351

[6] Locatelli C, Torsi G. J Electroanal Chem, 2001, 509: 80

[7] Beitollahi H, Sheikhshoaie I. J Electroanal Chem, 2011, 661: 336

[8] Zhao J, Zhang Y, Wu K B, Chen J W, Zhou Y K. Food Chem, 2011, 128: 569

[9] Karim-Nezhad G, Pashazadeh S, Pashazadeh A. Chin J Catal (催化 学报), 2012, 33: 1809

[10] Beitollahi H, Mohadesi A, Khalilizadeh Mahani S, Karimi-Maleh H, Akbari A. TurkJ Chem, 2012, 36: 526

[11] Raoof J B, Ojani R, Baghayeri M. Chin J Catal (催化学报), 2011, 32: 1685

[12] Habibi B, Abazari M, Pournaghi-Azar M H. Chin J Catal (催化学报), 2012, 33: 1783

[13] Beitollahi H, Sheikhshoaie I. Electrochim Acta, 2011, 56: 10259

[14] Moore R R, Banks C E, Compton R G. Anal Chem, 2004, 76: 2677

[15] Pumera M, Merkoci A, Alegret S. Sen Actuators B, 2006, 113: 617

[16] Rubianes M D, Rivas G A. Electrochem Commun, 2003, 5: 689

[17] Beitollahi H, Mohadesi A, Mohammadi S, Akbari A. Electrochim Acta, 2012, 68: 220

[18] Ju S P, Weng M H, Lin J S, Lu J M, Chang J G, Wu W H. Chin J Catal (催化学报), 2008, 29: 1113

[19] Beitollahi H, Raoof J B, Karimi-Maleh H, Hosseinzadeh R. J Solid State Electrochem, 2012, 16: 1701

[20] Beitollahi H, Karimi-Maleh H, Khabazzadeh H. Anal Chem, 2008, 80: 9848

[21] Voet D, Voet G J. Biochemistry. II Ed. New York: Wiley, 1995

[22] Agüí L, Manso J, Yáñez-Sedeño P, Pingarrón J M. Talanta, 2004, 64: 


\section{Graphical Abstract}

Chin. J. Catal, 2013, 34: 1333-1338 doi: 10.1016/S1872-2067(12)60582-8

Electrocatalytic measurement of methionine concentration with a carbon nanotube paste electrode modified with benzoylferrocene

Hadi BEITOLLAHI*, Alireza MOHADESI, Farzaneh GHORBANI, Hassan KARIMI MALEH, Mehdi BAGHAYERI, Rahman HOSSEINZADEH Graduate University of Advanced Technology, Iran; Payame Noor University, Iran; Hakim Sabzevari University, Iran; University of Mazandaran, Iran
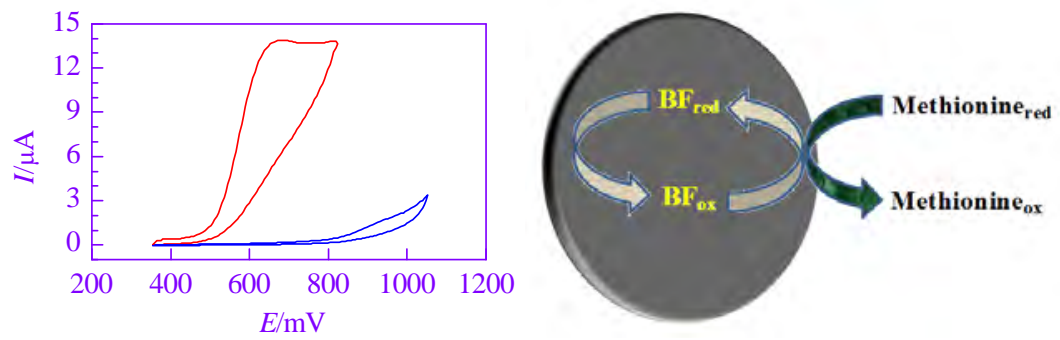

A sensor was fabricated for the measurement of methionine concentration that reduced the oxidation potential of methionine as compared to the unmodified electrode.

1041

[23] Zinellu A, Sotgia S, Usai M F, Zinellu E, Posadino A M, Gaspa L, Chessa R, Pinna A, Carta F, Deiana L, Carru C. Anal Biochem, 2007, 363: 91

[24] Selhub J. Annu Rev Nutr, 1999, 19: 217

[25] Giles W H, Croft J B, Greenlund K J, Ford E S, Kittner S J. Am Heart J, 2000, 139: 446

[26] Jocelyn P C. Biochemistry of the SH Group. London: Academic Press, 1972

[27] Hoshi T, Heinemann S H. J Physiol, 2001, 531: 1

[28] Cox J A, Dabek-Zlotorzynska E. Electroanalysis, 1991, 3: 239

[29] Catalá Icardo M, Armenta Estrela O, Sajewicz M, Garcla Mateo JV, Martınez Calatayud J. Anal Chim Acta, 2001, 438: 281

[30] Houze P, Gamra S, Madelaine I, Bousquet B, Gourmel B. J Clin Lab Anal, 2001, 15: 144

[31] Khan M I, Iqbal Z.J Chromatogr B, 2011, 879: 2567

[32] Fang G Zh, Liu N. Anal Chim Acta, 2001, 445: 245

[33] Hosseini M, Abkenar S D, Chaichi M J, Ganjali M R, Norouzi P. Spectrochim Acta A, 2009, 72: 484
[34] El-Brashy A M, Al-Ghannam Sh M. Anal Lett, 1996, 29: 2713

[35] El-Brashy A M, Al-Ghannam S M. Pharm World Sci, 1995, 17: 54

[36] Vasantha M S, Moorjani M N, Sreenivasan K S. Biochem Biophys Res Commun, 1970, 41: 568

[37] Yamasaki-Yashiki S, Tachibana S, Asano Y. Anal Biochem, 2012, 428: 143

[38] John Jeevagan A, Abraham John S. Bioelectrochemistry, 2012, 85: 50

[39] Xu H H, Zhang W, Zhu W, Wang D, Ye J, Yamamoto K, Jin L T. Anal Chim Acta, 2005, 545: 182

[40] Gomez-Mingot M, Iniesta J, Monitel V, Kadara R O, Banks C E. Sens Actuators B, 2011, 155: 831

[41] Cheng L, Pacey G E, Cox J A. Anal Chem, 2001, 73: 5607

[42] Enache T A, Oliveria-Brett A M. Bioelectrochemistry, 2011, 81: 46

[43] Tan W T, Goh J K. Electroanalysis, 2008, 20: 2447

[44] Bard A J, Faulkner L R. Electrochemical Methods: Fundamentals and Applications. 2nd Ed. New York: Wiley, 2001

[45] Tabeshnia M, Rashvandavei M, Amini R, Pashaee F. J Electroanal Chem, 2010, 647: 181 